\title{
An approach for a sustainable decision-making in product portfolio design of dairy supply chain in terms of environmental, economic and social criteria
}

\section{Elisaveta Georgieva Kirilova ( $\sim$ e.kirilova@iche.bas.bg )}

Bulgarian Academy of Sciences https://orcid.org/0000-0002-9984-5067

Natasha Vaklieva-Bancheva

Bulgarian Academy of Sciences

\section{Rayka Vladova}

Bulgarian Academy of Sciences

\section{Tatyana Petrova}

Bulgarian Academy of Sciences

\section{Boyan Ivanov}

Bulgarian Academy of Sciences

\section{Desislava Nikolova}

University of Burgas

\section{Yunzile Dzhelil}

\section{Bulgarian Academy of Sciences}

\section{Research Article}

Keywords: Optimal product, portfolio design, Supply chain, Social sustainability, Dairy industry, Decisionmaking process

Posted Date: February 19th, 2021

DOl: https://doi.org/10.21203/rs.3.rs-238627/v1

License: (c) (i) This work is licensed under a Creative Commons Attribution 4.0 International License. Read Full License

Version of Record: A version of this preprint was published at Clean Technologies and Environmental Policy on June 2nd, 2021. See the published version at https://doi.org/10.1007/s10098-021-02110-2. 


\section{Abstract}

The production of dairy products is related to water and energy costs and generation of large amounts of greenhouse gas (GHG) emissions and wastewater. This has a direct bearing on the reduction of natural resources, the negative impact on the environment as well as the rise of social concerns due to increased product costs, pollution, etc. Full sustainability of this type of systems can be achieved by optimizing all activities across the chain of raw materials, through production to customers while considering all aspects of sustainability - environmental, economic and social. The study proposes a multi-objective modelling approach for optimal design of three-echelon supply chain (SC) for production of dairy products according to different recipes where all aspects of sustainability are taken into consideration. The approach was implemented on a real case study from Bulgaria. Four mix integer nonlinear programming (MINLP) optimization models were defined without and with social impact consideration. They are solved using General Algebriac Modeling System (GAMS) software. The obtained results have shown how the social impact assessment affects the obtained optimal products portfolios and profits. In these cases, varying the values of environmental constraints also affect the products portfolios and profits without affect the social costs. The stricter constraints on the environment impact leads to higher economic costs and lower profits, and conversely, high values of environmental constraints result in higher profits and lower economic costs. The obtained solutions can be used in the decision-making process to achieve social sustainability of the considered dairy supply chain.

\section{Full Text}

Due to technical limitations, full-text HTML conversion of this manuscript could not be completed. However, the manuscript can be downloaded and accessed as a PDF.

\section{Figures}




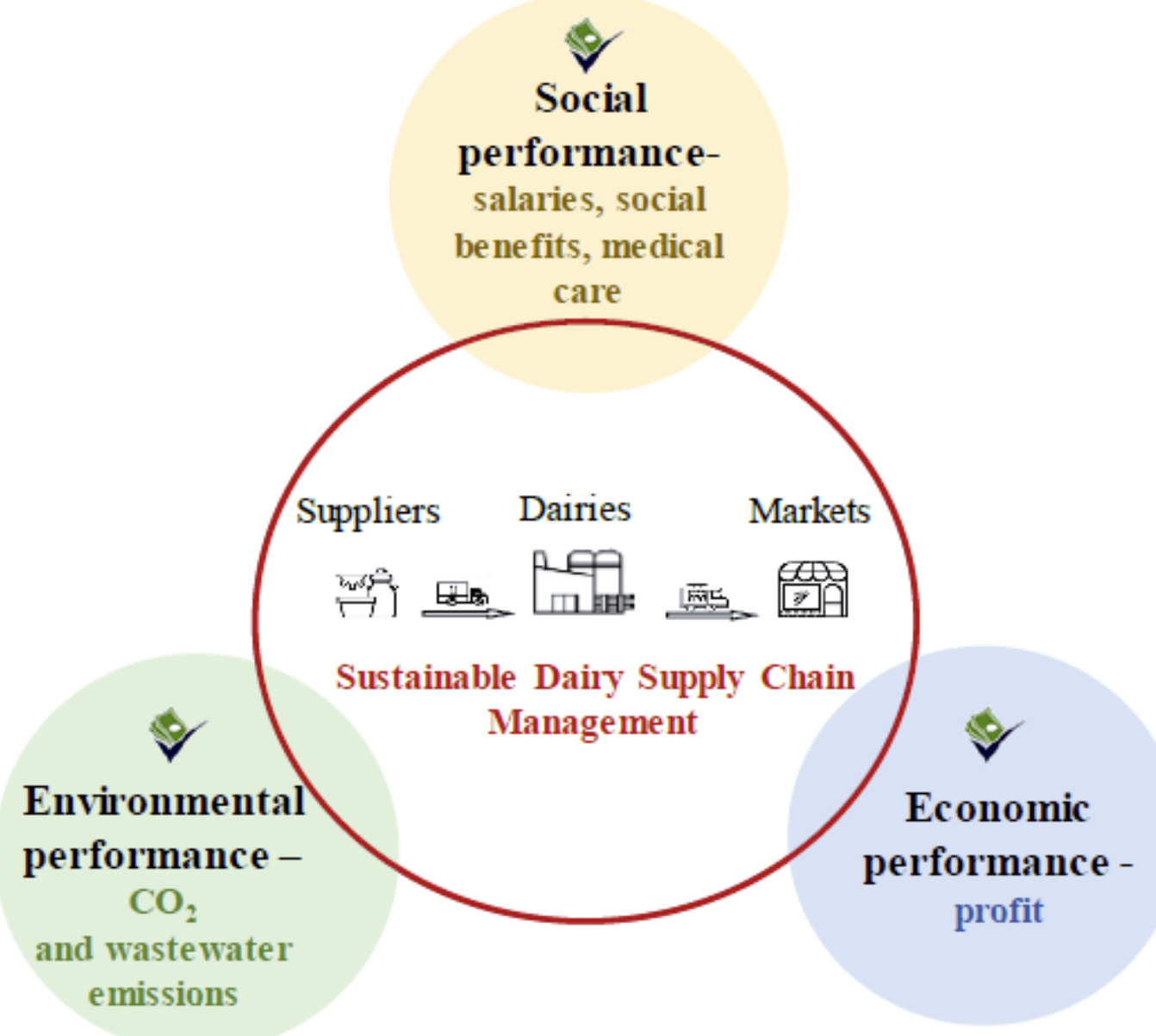

Figure 1

Optimization approach for a sustainable decision-making in product portfolio design of dairy supply chain. 
Dairy 1

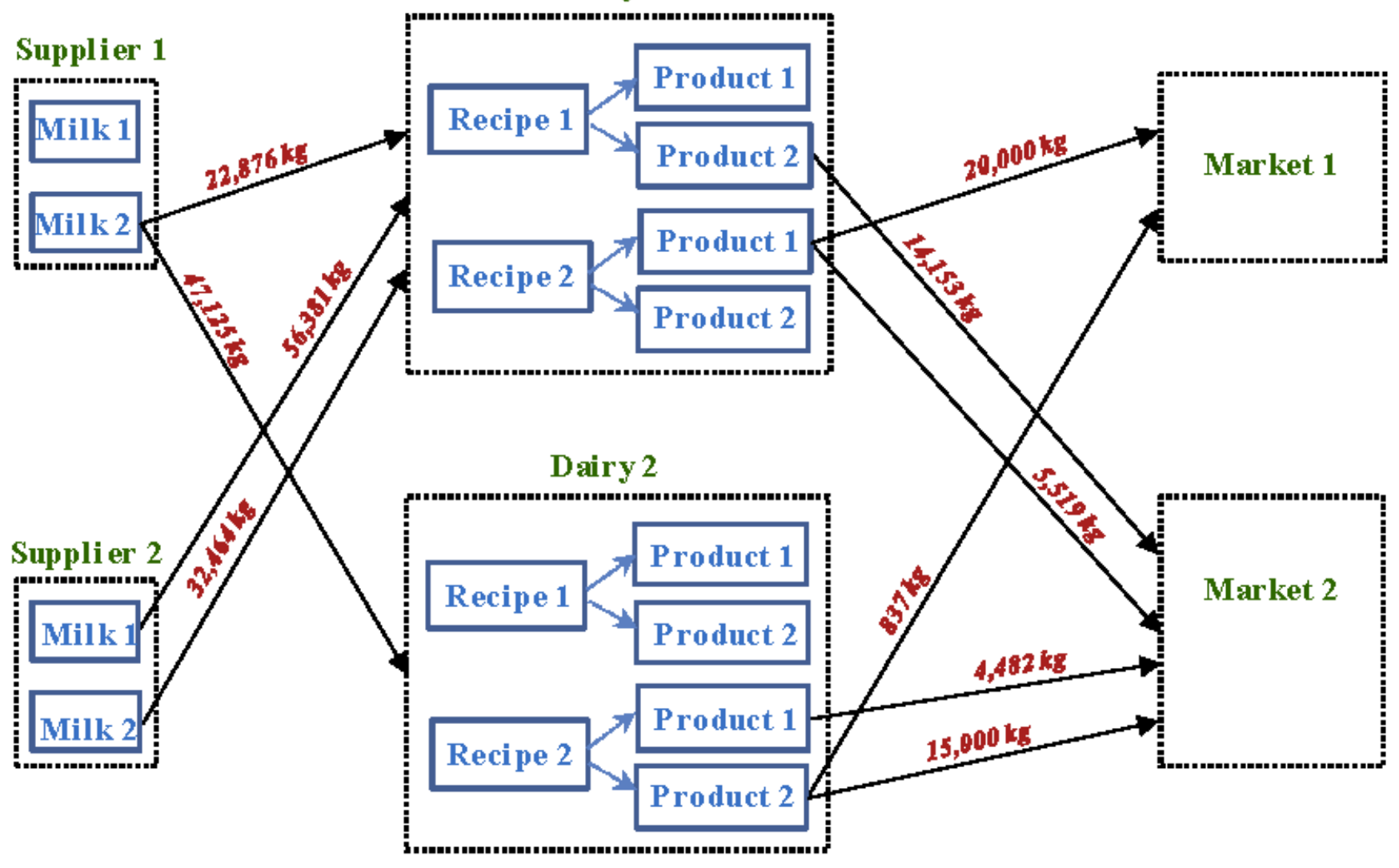

Figure 2

Optimal products portfolio of dairy SC for Solution 1. 
Dairy 1

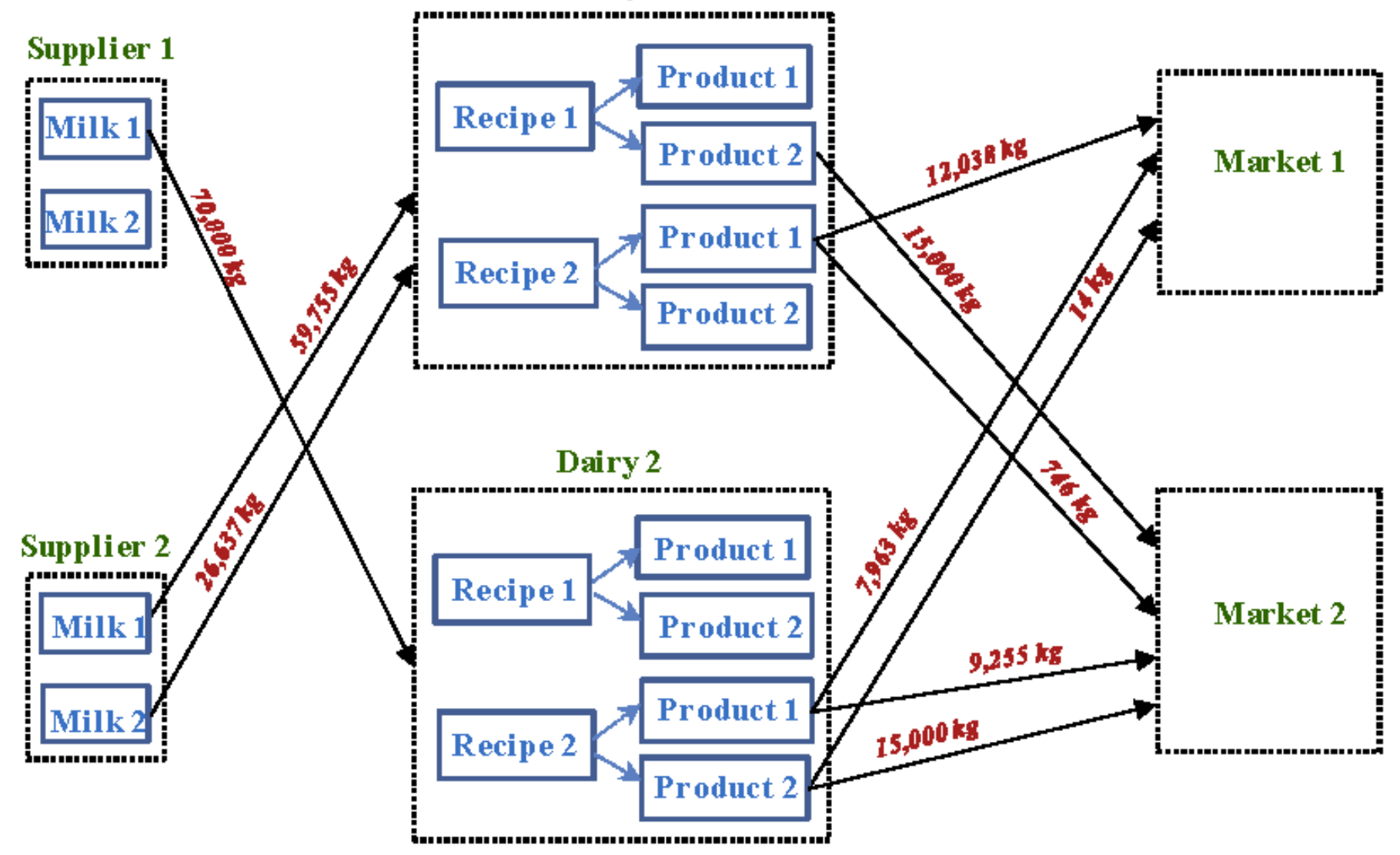

Figure 3

Optimal products portfolio of dairy SC for Solution 2. 


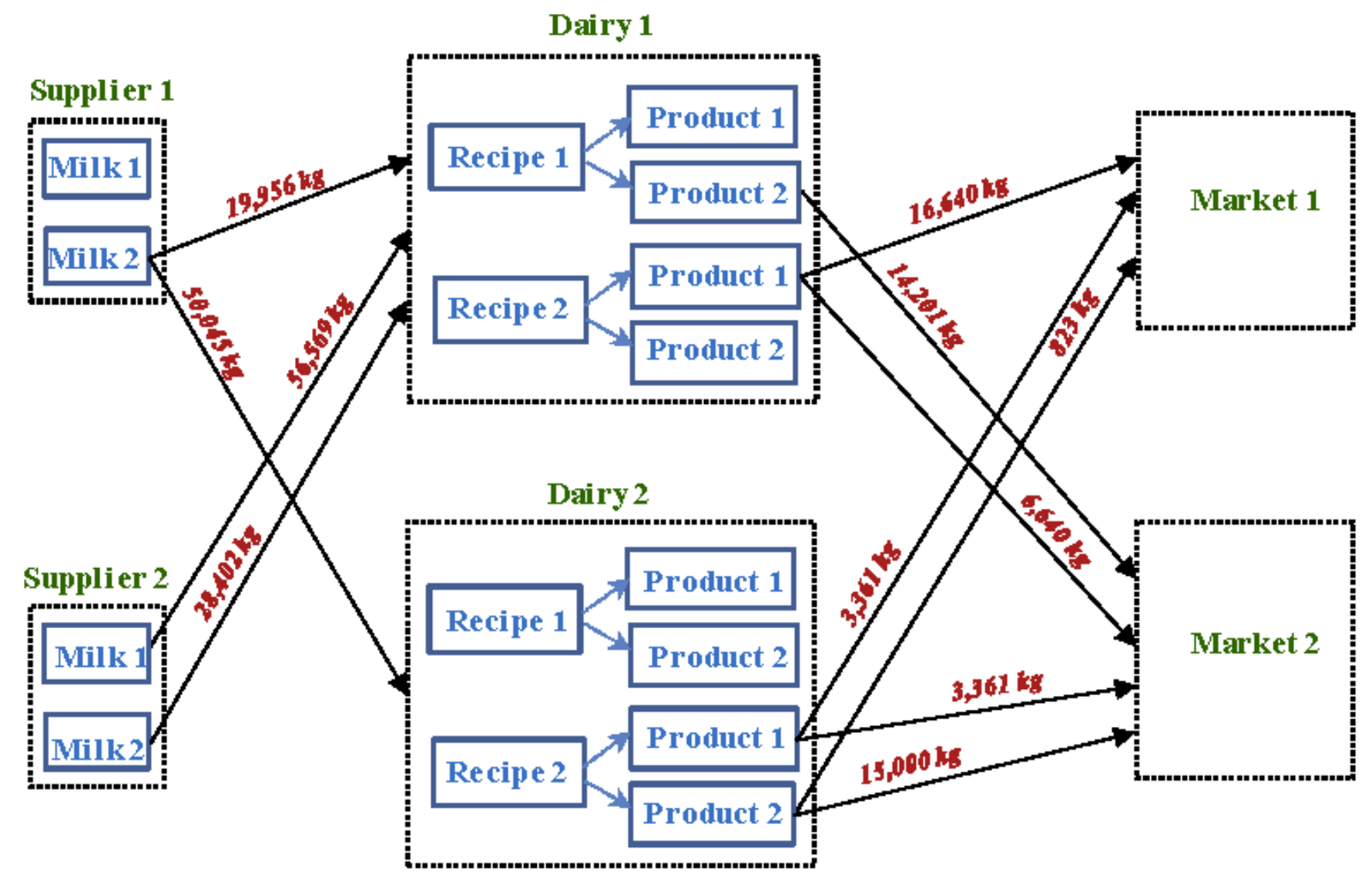

Figure 4

Optimal products portfolio of dairy SC for Solution 3. 


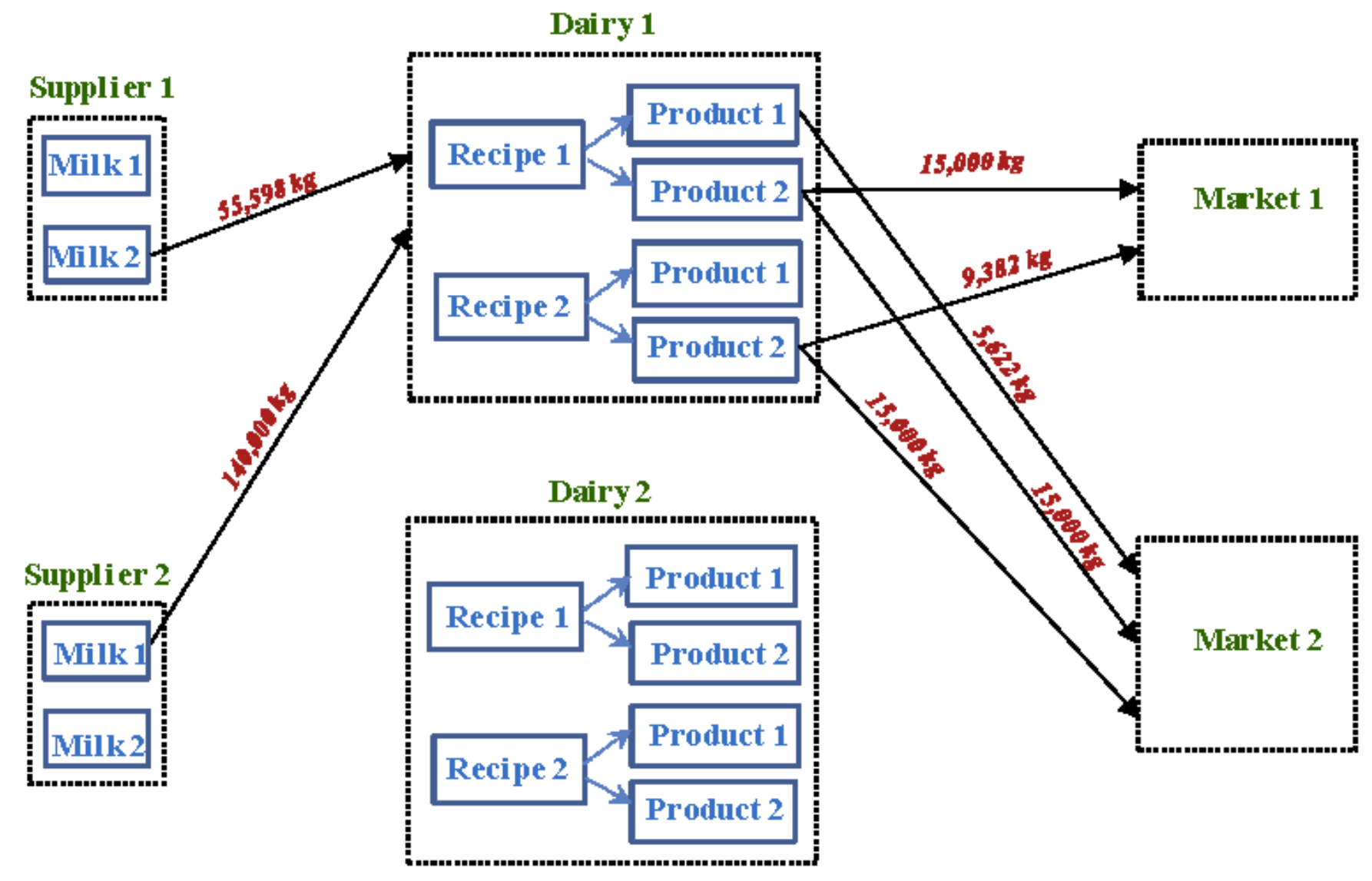

Figure 5

Optimal products portfolio of dairy SC for Solution 4.

\section{Supplementary Files}

This is a list of supplementary files associated with this preprint. Click to download.

- Graphicalabstract.pdf 